\title{
OS CENÁRIOS DA PANDEMIA: A GEOGRAFIA, O ENSINO REMOTO E A ESCOLA ${ }^{1}$

\author{
THE PANDEMIC SCENARIOS: \\ GEOGRAPHY, REMOTE EDUCATION AND SCHOOL
}

\author{
Ana Carla Lenz ${ }^{2}$, Ana Paula Kiefer ${ }^{3}$, \\ Lucian Armindo da Silva Brinco ${ }^{4}$ e Natália Lampert Batista ${ }^{5}$
}

\section{RESUMO}

O presente artigo dialoga sobre a importância do ensino de Geografia e do professor da disciplina para a construção da interpretação crítica do espaço geográfico (vivido ou não) pelos estudantes, sobre o ensino remoto em tempos de pandemia e a escola enquanto lugar, não só de ensino e aprendizagem, mas também de pertencimento. Para tal, fez-se uso da abordagem qualitativa, de revisão teórica e de pesquisa de "campo virtual", por meio do aplicativo de mensagens instantâneas de texto, de voz e de vídeos, WhatsApp, nos meses de maio, junho e julho de 2020. Observou-se que o isolamento social tem despertado inúmeras inquietações tanto para estudantes como para professores, bem como que a escola é um lugar essencial a comunidade escolar, para além do papel de escolarização, mas também de construção de identidades e de conhecimentos geográficos. Assim, conclui-se que a pandemia reitera a importância da presença o professor, do estudante e de toda a comunidade escolar no lugar-escola, bem como que o ensino remoto, por mais abrangente que se proponha, não dá conta das peculiaridades dos contextos vividos pelos estudantes e docentes imbricados no ensino de Geografia.

Palavras-chave: COVID-19, novo Coronavírus, ensino de Geografia.

\section{ABSTRACT}

This article discusses the importance of teaching Geography and the teacher of the discipline for the construction of critical interpretation of geographic space (lived or not) by students, about remote teaching in times of pandemic and school as a place, not only for teaching and learning, but also belonging. To this end, the qualitative approach, theoretical review and "virtual field" research was used, using the text, voice and video instant messaging application, WhatsApp, in the months of May, June and July 2020. It was observed that social isolation has aroused numerous concerns for both students and teachers, as well as that the school is an essential place for the school community, in addition to the role of schooling, but also of building identities and geographical knowledge. Thus, it is concluded that the pandemic reiterates the importance of the presence of the teacher, the student and the entire school community in the school place, as well as that remote education, however comprehensive it may be proposed, does not account for the peculiarities of the contexts experienced by students and teachers involved in the teaching of Geography.

Keywords: COVID-19, new Coronavirus, teaching Geography.

\footnotetext{
${ }^{1}$ Trabalho de Pesquisa - Universidade Federal de Santa Maria - UFSM.

${ }^{2}$ Doutoranda em Geografia - Universidade Federal de Santa Maria - UFSM. E-mail: anacarlalenz@gmail.com

${ }^{3}$ Graduanda em Geografia - Universidade Federal de Santa Maria - UFSM. E-mail: anapaulakiefer@gmail.com

${ }^{4}$ Graduado em Geografia - Universidade Federal de Santa Maria - UFSM. E-mail: lucianbrinco@gmail.com

${ }^{5}$ Orientadora - Pós-doutoranda em Geografia - Universidade Federal de Santa Maria - UFSM. E-mail: natilbatista3@ gmail.com
} 


\section{INTRODUÇÃO}

Em tempos de isolamento social, as práticas de ensino de Geografia precisaram se adequar ao contexto de excepcionalidade que distanciou de maneira física (e emocional) a comunidade escolar da escola. A COVID-19 afastou os estudantes e professores das salas de aula, mas demostrou como nunca a necessidade desta interação para a produção de conhecimentos escolares, por meio da troca, da presença e da coparticipação na construção de saberes geográficos. As consequências desse período, deste modo, reafirmam a importância do convívio escolar para a formação, não apenas de alunos, mas também dos demais membros da comunidade escolar. Nesse sentido, ao pensar a escola como essência, isto é, seguindo o pensamentos de Ferreira (2002, p. 47), como o lugar chave do encontro para a aprendizagem e escolarização, tem-se que "O lugar seria, então, o 'centro profundo da existência humana' cuja essência estaria na intencionalidade grandemente não-autoconsciente".

De encontro com essa perspectiva, a sala de aula, os ambientes de diversão da escola e todos os lugares que proporcionam interação entre professores, funcionário e alunos, podem ser compreendidos como o mundo vivido (BUTTIMER, 1982). Além disso, a interação e comunicação com outras pessoas que transitam pela escola transformam o indivíduo, ao mesmo tempo em que se constituem como ponto de referência física e, principalmente, emocional para a construção da personalidade dos estudantes. É nesse contexto que a Geografia, enquanto ciência multidisciplinar, contribui para o desenvolvimento dos vinculados ao sentimento de "pertencer a algo" ou a um lugar.

Isso porque os professores de Geografia buscam correlacionar os conteúdos curriculares com as peculiaridades locais. Essa é uma forma de fazer com que esses conhecimentos tenham sentido para os estudantes e que se tornem palpáveis em sua imaginação e interpretação do mundo. Seguindo essa linha de pensamento, o presente artigo dialoga sobre: a importância do ensino de Geografia e do professor da disciplina para a construção da interpretação crítica do espaço geográfico (vivido ou não) pelos estudantes; e o ensino remoto em tempos de pandemia e a escola enquanto lugar não só de ensino e aprendizagem, mas também de pertencimento. Para tal, fez-se uso da abordagem qualitativa, de revisão teórica e pesquisa de "campo virtual", por meio do aplicativo de mensagens instantâneas de texto, de voz e de vídeos, WhatsApp.

As entrevistas ocorreram em maio, junho e julho de 2020. As mesmas foram e estão sendo encaminhadas a professores da área e são referentes às suas práticas docentes no período de pandemia, bem como a estudantes da Educação Básica, prioritariamente do $3^{\circ}$ ano do Ensino Médio, os quais são diretamente impactados pelo distanciamento social e ensino remoto, bem como pelas incertezas que permeiam seu futuro breve. Para entender como os alunos estão se adaptando ao ensino remoto foi solicitada a inserção de alguns dos pesquisadores em grupos de diferentes turmas na plataforma WhatsApp. Assim, podem-se fazer questionamentos diretamente a eles, sem mediadores. Para esse artigo, selecionaram-se cinco narrativas, todas sem identificação dos estudantes e de suas escolas. 
A importância do presente texto está em transmitir o olhar dos sujeitos que vivenciam diariamente as dificuldades e os encantos do ensino de Geografia e do lugar onde ele ocorre oficialmente: a escola. Destacam-se também os enfrentamentos atuais, em período de isolamento social, devido à pandemia do COVID-19, desses sujeitos como a falta de experiências, de encontros, de diálogos em espaços físicos de socialização, de trocas presenciais, que afetam o cotidiano, as expectativas e a vida como um todo dos estudantes e suas famílias, dos professores, dos funcionários, de toda a comunidade escolar. Na sequência, será debatida a importância do ensino de Geografia e, posteriormente, os cenários do ensino remoto frente a essa disciplina escolar e o lugar a escola ou a escola como lugar.

\section{ENSINO DE GEOGRAFIA E A SUA IMPORTÂNCIA PARA A SOCIEDADE}

Para promover a educação da criança, do jovem e do adulto, faz-se o uso de diferentes processos voltados ao desenvolvimento de metodologias de ensino e aprendizagem. Diferentes orientações curriculares discorrem sobre as habilidades, competências, metodologias e estratégias a serem adotadas em sala de aula. No entanto, as vivencias cotidianas e as características do lugar, são peculiares a cada Instituição de ensino. Essas orientações, mais contemporaneamente, estão abrindo espaço para pensar os lugares de vivências dos estudantes, refletir sobre onde ocorrem as experiências, as trocas do cotidiano que envolvem os núcleos familiares, as comunidades, os diferentes espaços e sujeitos. Isso remonta a necessidade de saber "onde estamos", "por que estamos" e "o que queremos" com a educação e com as metodologias de ensino que adotada. A Geografia, neste interim, se torna chave para o entendimento das relações glocais (interrelação lugar e global) e para a compreensão do espaço de vivência dos estudantes (BATISTA, 2015).

A valorização dos saberes tradicionais e de práticas humanizadoras, que levem a uma integração entre os saberes populares e os saberes técnicos científicos, é central ao ensino de Geografia, em contexto pandêmico ou não. Com isso, os professores de Geografia buscam correlacionar os conteúdos curriculares com as peculiaridades da paisagem e do lugar que a escola faz parte/pertence, seguindo a orientação da BNCC (BRASIL, 2018), com os saberes e fazeres locais, à cultura. Dessa forma, visa-se aproximar à escola da comunidade e à comunidade da escola, favorecendo o sentimento de pertencimento ao lugar. Como também essa prática contribui para a visualização das problemáticas socioeconômicas, ambientais e culturais existentes nos lugares.

A partir da elucidação das mais diversas problemáticas, os alunos, os professores, os gestores, os pais e a sociedade podem pensar juntos em soluções para sanar tais dificuldades. A afirmativa é apenas uma das características favoráveis ao ensino de Geografia, por meio delas, pode-se, também, visualizar a importância do professor da disciplina, por ser ele o mediador da interação dos conhecimentos herdados locais com os conteúdos curriculares obrigatórios (LENZ; BATISTA; DE DAVID, 2019). 
Nesse contexto, Serpa (2020) enfatiza que:

O mundo aí fora tem uma Geografia e essa Geografia se pratica no dia a dia. O sentido de praticar Geografia pode se revelar ou se ocultar para nós, a depender de nossa atitude - consciente ou inconsciente - no cotidiano. Percebida ou não de modo consciente, essa Geografia é constituída de habilidades que, juntas, como 'proezas' e de modo imbricado, criam e produzem nossos espaços de vida (cotidiana) (SERPA, 2020, p. 438).

Assim sendo, vale destacar que os docentes de Geografia possuem um papel fundamental na mobilização e/ou formação de sujeitos que intervenham de forma articulada, crítica e reflexiva nos espaços pelos quais estão inseridos. A Geografia Escolar, através disso, possibilita que os alunos percebam os fenômenos que se processam de modo explícito e, em muitos casos, de maneira oculta em seus cotidianos. É por meio das problematizações a respeitos das desigualdades sociais, econômicas, dos problemas ambientais, por exemplo, que o ensino de Geografia colabora para a transformação da realidade local e, desse modo, para a construção de um mundo mais justo.

Logo, infere-se que tanto o profissional quanto os conteúdos programáticos da Geografia escolar favorecem o trabalho interdisciplinar, multidisciplinar no ambiente escolar e extraescolar. Por enquanto, esse diálogo ocorre quando o ensino é presencial, quando se tem o contato físico com pessoas e com os objetos.

\section{OS CENÁRIOS DO ENSINO REMOTO}

Esses momentos de diálogo, trocas e reflexões entre professores e alunos, entretanto, foram bastante prejudicados nos últimos meses devido a pandemia do COVID - 19, que se caracteriza por ser uma mutação do novo coronavírus, surgida na cidade de Wuhan, na China. Vírus que tardou apenas dois meses para chegar ao Brasil e fazer a sua primeira vítima, um homem de 62 anos, dia 16 de março, um dia após o início do isolamento social no país e no Estado do Rio Grande do Sul (RIZZATTI et al., 2020; VARGAS; LAWALL, 2020). A partir daí as aulas passaram a ser ministradas por meio do ensino remoto. Alunos e professores tiveram que, praticamente, do dia para a noite, fazer uso dessa modalidade "[...] como uma possibilidade de suprir parte do currículo e/ou manter o vínculo escolar dos estudantes" (FERREIRA; TONINI, 2020, p. 27).

Para tanto, com a readequação do ensino para o modelo remoto não apenas os alunos foram desafiados a aprender uma nova forma de assimilação dos conteúdos programáticos, mas professores e pais também tiveram (e estão tendo) que rever o conceito de educação e de ensino para se adequar à nova e momentânea situação imposta pela pandemia.

No contexto evidenciado, os desafios começaram a aflorar, principalmente quando o uso e o acesso às tecnologias não é uma realidade de todos os estudantes e professores em Santa Maria, por exemplo. Conjunturas outrora silenciadas passam a gritar por soluções. Todavia, muitas das soluções 
apontadas como imediatas se tornam paliativas e fragmentadas frente à complexa realidade de nosso país. Falta-nos um plano nacional de enfrentamento da COVID-19 e isso repercute diretamente nas ações tomadas em nível local e regional e, consequentemente, nos parâmetros que irão mediar os direcionamentos do ensino remoto. Estamos à deriva, tentando nos salvar. Logo, se por um lado o ensino remoto é a solução para a instrumentalização didático de professores e alunos, por outro a sua utilização pode ser um problema frente à desigualdade social em nosso país e relacionada a falta de acesso a infraestrutura básica para as aulas por professores e estudantes.

No Rio grande do Sul, as aulas da rede estadual foram suspensas quatro dias após o início do isolamento social. Ferreira e Tonini (2020), sobre essa questão, observam que:

[...] logo no início do isolamento social, o Conselho Nacional de Educação (CNE) encontrou amparo na própria Lei de Diretrizes e Bases da Educação Nacional (LDB), que prevê parcialmente o ensino à distância como complementação da aprendizagem em situações emergenciais no ensino fundamental e, recentemente, para o ensino médio, a possibilidade de convênios com instituições de ensino à distância. Assim, aproximadamente após um mês da primeira orientação, o mais recente documento do CNE aprova as atividades de forma remota, por meio digital ou não, e deixa para que conselhos estaduais e municipais de Educação possam definir como cada localidade seguirá as orientações, dando autonomia às redes e instituições. (FERREIRA; TONINI, 2010, p. 28).

Por esse motivo o decreto do Estado contemplou as aulas da rede pública e privadas do município de Santa Maria. Assim, no município ficou estabelecido que,

Ficam suspensos, diante das evidências científicas e análises sobre as informações estratégicas em saúde, observado o indispensável à promoção e à preservação da saúde pública, para fins de prevenção e de enfrentamento à epidemia causada pela Covid-19 (novo Coronavírus), com fundamento no art. $3^{\circ}$ da Lei Federal $n^{\circ} 13.979$, de 6 de fevereiro de 2020, as aulas, cursos e treinamentos presenciais em todas as escolas, autoescolas, faculdades, universidades, públicas ou privadas, municipais, estaduais ou federais, e demais instituições de ensino, de todos os níveis e graus, bem como em estabelecimentos educativos, de apoio pedagógico ou de cuidados a crianças, incluídas as creches e pré-escolas, situadas em todo o território do Estado do Rio Grande do Sul. (RIO GRANDE DO SUL, 2020, s/p).

As ações tomadas visavam à preservação e promoção da saúde pública por meio do afastamento social. Contudo, elas também revelaram as disparidades existentes entre as três redes de ensino aqui referidas: estadual, municipal e privada. Enquanto a rede particular manteve o contato imediato com os seus alunos, por meio da utilização de dispositivos eletrônicos e fornecendo conteúdos impressos, como relata o depoente A: “[...] os professores na rede particular se tornaram 'YouTubers', as aulas não param e o professor teve que se virar, aprender a produzir e a gravar vídeos aulas" (Narrativa 1 - Via WhatsApp em 21 de mai. 2020). As redes públicas demoraram um pouco mais para a adaptação ao ensino remoto. Isso bastante associado às características os públicos atendidos pelas redes de ensino mencionadas e, consequentemente, da demanda de soluções para as desigualdades 
de acesso as mídias expostas pela pandemia (que ainda permanecem uma incógnita de como será efetivamente resolvida, para além dos discursos bonitos).

O depoente A destaca, ainda, que nas escolas públicas que leciona o ensino remoto ocorreu lentamente por não se ter uma plataforma definida. Destaca, também, que tanto na rede estadual quanto municipal o pedido foi que não se contemplasse conteúdos novos, que as atividades de envio, por meio de material impresso, fossem somente de revisão, ou seja, do que já foi trabalhado nas aulas presenciais. (Narrativa 1 - Via WhatsApp em 21 de mai. 2020).

No "salvamento" do ano letivo, através do ensino remoto, revela-se que foi desconsiderada as dessemelhanças nas infraestruturas das redes de ensino e das comunidades escolares (FERREIRA; TONINI, 2020). Segundo as autoras, o Fundo das Nações Unidas para a Infância (UNICEF) alertou que, 4.8 milhões de crianças e adolescentes, na faixa etária de 9 a 17 anos, não possuem acesso à internet em casa. Uma das desigualdades sociais não só santa-mariense, mas mundial que foi escancarada com a pandemia.

As autoras anteriormente citadas, Ferreira e Tonnini (2020, p. 39), também observaram que o descaso "[...] com as desigualdades espaciais existentes nas diversas escolas brasileiras é algo que, neste momento, se destaca provando que para além de um excesso de discursos de preocupação com a escola, há pouca consideração com o contexto no qual ela está inserida". A pandemia só confirmou o destacado por elas e agravou a situação dos mais vulneráveis em virtude das complicações no acesso às atividades, às escolas acumulando-se às dificuldades pré-existentes até mesmo de "[...] deslocamento dos estudantes até a escola como: distância, segurança, mobilidade, entre outras". (FERREIRA; TONINI, 2010, p. 29).

Essa disparidade se agrava nas escolas do meio rural do município de Santa Maria. Como revelado pelo depoente B: “[...] estamos enviando o material via transporte escolar porque muitos dos nossos alunos não tem como ir até à escola buscá-los" (Narrativa 2 - Via WhatsApp em 25 de mai. 2020). Segundo o depoente, também deve-se atentar para o fato de que "[...] pouco adiante enviar conteúdo para os alunos trabalharem em casa, visto que, geralmente os pais não têm escolaridade para ajudar os filhos ou paciência e, como são crianças do meio rural, muitas famílias estão aproveitando a quarentena para aproveitá-los como mão de obra extra" (Narrativa 3 - Via WhatsApp em 25 de mai. 2020).

Nesse sentido, Alves (2020, p. 355) comenta que "A dificuldade dos pais em orientar as atividades escolares, considerando o nível de escolaridade familiar, especialmente os pais dos alunos da rede pública se constitui em um entrave nesse momento". Certamente, muitos educados recorrem aos seus responsáveis para lhes auxiliarem, discutirem e sanarem as dúvidas que surgem acerca de um dado conteúdo, o que se torna muito positivo para ambos dentro desse processo educativo, mas também pode proporcionar limitações para eles em decorrência dos níveis de seus conhecimentos. 
Para Ferreira e Tonini (2020)

Esta invisibilidade do contexto escolar também se relaciona à acusação de que a escola facilitaria o aprofundamento de desigualdades sociais como instrumento de poder e insistiria em uma suposta autonomia e neutralidade, o que a faz acreditar numa igualdade de oportunidades, ou criar um tratamento desigual . Não é que a escola negue as desigualdades existentes no seu cotidiano, mas percebemos o motivo desta acusação nas medidas tomadas a partir do parecer do CNE que permite o ensino remoto. As mantenedoras tanto públicas quanto privadas, em sua maioria, o adotaram sem levar em conta as desigualdades que poderiam fomentar. Com este menosprezo pela heterogeneidade particular a cada escola os professores deixam de lado também está prioridade, pois estão assoberbados, por exemplo, por ter que aprender os sistemas para ensino remoto, continuar planejando atividades, corrigindo-as e ainda lecionar em salas de aula virtuais no mesmo horário das aulas presenciais (FERREIRA; TONINI, 2020, p. 29).

O contexto de despreocupação com alunos da rede pública de ensino é percebido não só por professores e gestores, mas também pelos próprios alunos. De acordo com alguns estudantes do terceiro ano do Ensino Médio da rede estadual de Santa Maria. As escolas demoram em disponibilizar o material impresso, criarem grupos no WhatsApp e desenvolverem as páginas (salas de aulas) no Google Classroom, mesmo que elas criadas o conteúdo programático, muitas vezes, não estava disponível como mostra a Figura 1, isso talvez por dificuldades tecnológicas em disponibilizá-los pelo professores ou em acessá-lo pelos alunos

Figura 1 - Conversa do grupo de WhatsApp do $3^{\circ}$ ano do Ensino Médio com destaque ao fato de que os materiais das páginas não estavam disponível para consulta dos estudantes.

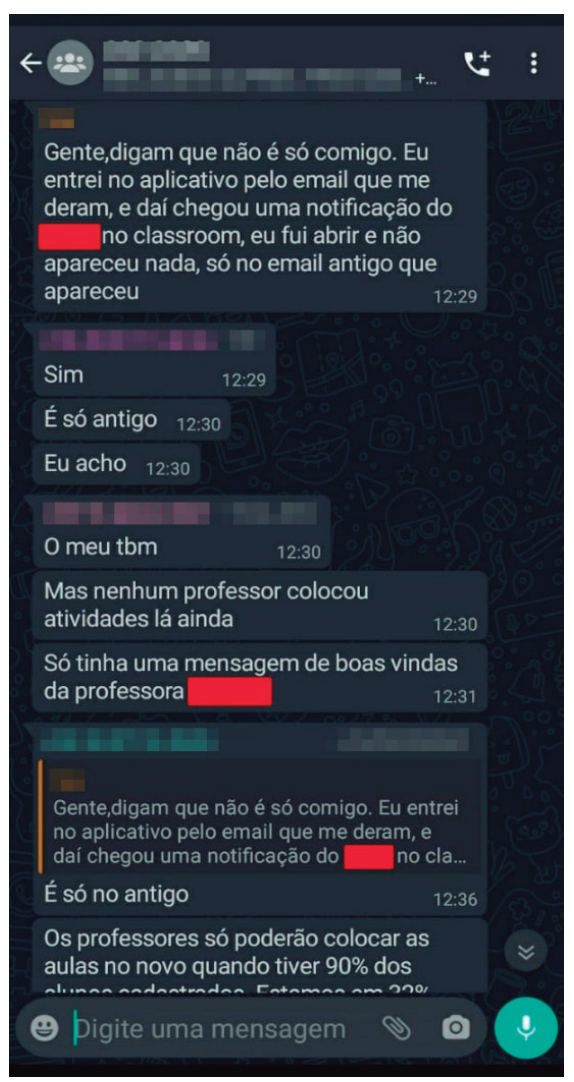

Fonte: Grupo de WhatsApp, 2020. 
A mensagem foi enviada por um aluno ao grupo no dia 06 de julho de 2020. Os relatos são de que o acesso ao conteúdo programático está difícil, o material impresso fornecido pelas escolas não supre as necessidades de aprendizagens, assim com de preparação para o Enem. Mas de acordo com os professores,

\begin{abstract}
As escolas estaduais começaram o ensino remoto em 19 de março. A adesão dos alunos está crescendo aos poucos. Um número considerável não envia as atividades, mas não é só pelo difícil acesso à internet, mas também por não encontrarem motivação para o estudo EAD e pelas situações sociais em seus lares. Percebemos o quanto o professor e a escola fazem falta na vida escolar e pessoal dos alunos. (Narrativa 4 - Via WhatsApp em 06 de jul. 2020).
\end{abstract}

Sendo assim, nota-se que a falta de acesso às plataformas digitais por muitos alunos é uma situação que foi relatada novamente pelos professores. No entanto, os docentes também colocam que conseguir estimular os educandos através do ensino remoto é algo bastante complicado. É nesses momentos que, mais uma vez, percebe-se a importância dos profissionais da educação no desenvolvimento de cada um desses discentes. Além disso, o descrito é comprovado com a resposta à questão levantada pelo aluno disponível na Figura 2.

Figura 2 - Conversa do grupo de Whatssap do $3^{\circ}$ ano do Ensino Médio.

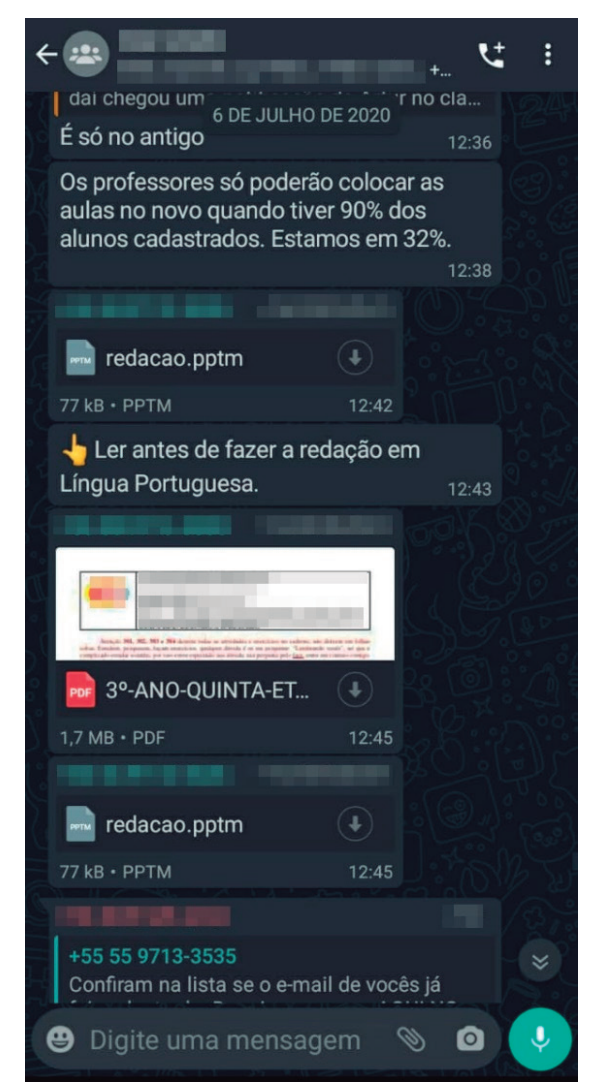

Fonte: Grupo de WhatsApp, 2020.

Outra questão que a Figura 2 mostra é que os professores estão se esforçando para atender as demandas surgidas com pandemia, por meio de envio de material impresso e digitais. Contudo, como 
destacado na Narrativa 4, a escola como lugar de aprendizado e de encontro está fazendo falta na vida das pessoas, principalmente, na dos alunos.

Nessa perspectiva, a inclusão das tecnologias nos diferentes níveis da educação ganhou uma notoriedade muito significativa nos últimos anos e, em especial, neste período de isolamento social. Já não é novidade o fato de que tais recursos didáticos proporcionam aulas diferenciadas, mais lúdicas e/ou atraentes. Pimentel, Araújo e Oliveira (2020, p. 4), entretanto, alertam que o acesso dos alunos às plataformas virtuais neste momento de pandemia envolve questões bastante complexas. É necessário que se pense acerca dos aspectos sociais, econômicos e culturais dos educandos, e, do mesmo modo, nas adversidades encontradas em uma rede de ensino profundamente heterogênea. A Geografia, neste contexto, colabora com o entendimento e com a leitura dessa realidade, fazendo com que não se tenha um olhar ingênuo de que basta produzir um material interessante que os alunos irão acessar as aulas. É preciso entender que a docência, em tempos de COVID-19, vai além da prática pedagógica remota, mas inclui pensar criticamente e desenvolver uma postura ativa frente às desigualdades sociais, para que as "soluções paliativas" ao "salvamento" do ano letivo não se tornem discursos falaciosos apenas em vias oficiais de registro, quando na prática o estudante e o próprio professor permanecem "remando contra a maré".

Segundo Alves (2020), a tecnologia é um complemento didático que, se conduzido de maneira correta, desencadeia resultados muito positivos para a assimilação dos conteúdos pelo educando. A autora enfatiza, porém, que o recurso tecnológico utilizado nas práticas pedagógicas é importante, “[...] mas não contribui para aprendizagem e práticas colaborativas entre os sujeitos do processo de ensinar e aprender (ALVES, 2020, p. 358)". Paradoxalmente, essa mesma tecnologia que pode aproximar em terreno emergencial, também pode limitar o acesso face às desigualdades sociais e a falta de alfabetização e letramento tecnológico de docentes e discentes. O novo Coronavírus marca a acentuação das extremidades e nos vemos emaranhados entre o agir e o paralisarmos frente a tamanhas dicotomias que nos assolam no cotidiano.

\section{O LUGAR DA ESCOLA: A ESCOLA COMO LUGAR}

O isolamento social em virtude da pandemia afastou toda a comunidade escolar de escolar: lugar esse que se fortalece acerca das trocas de experiências, de ensino e aprendizado. Fenômeno que está favorecendo o desenvolvimento de doenças psicológicas, como manifestou o depoente D: “[...] alunos, professores e funcionários estão apresentando sintomas de ansiedade, stress, choro, angústia, desânimo" (Narrativa 4 - Via WhatsApp em 06 de jul. 2020). Deixa claro, ainda, que o ambiente escolar contribui não só com o processo de ensino e aprendizagem, mas também para com o processo de socialização, o qual é muito importante para a manutenção e promoção da saúde física e psicológica de toda a comunidade escolar, não somente dos alunos (Narrativa 4 - Via WhatsApp em 06 de jul. 2020). 
Seguindo a linha de pensamento, observa-se que a escola, enquanto lugar de experiências, de trocas, de afetos, não pode ser substituída por salas de aulas online, claro que, no momento vivido, de pandemia, elas são essenciais. Contudo, no pós-pandemia, acredita-se na correlação, na união do ensino remoto com o presencial para a promoção do ensino de Geografia. Mas, ressalva-se que a escola, enquanto lugar onde ocorre os contatos físicos com pessoas e objetos, é importante para a saúde física e mental dos sujeitos.

É nesse contexto que a Geografia enquanto ciência multidisciplinar, pela a abrangência de inúmeros conceitos que fundamentam o seu ensino, a sua pesquisa e os seus estudos geográficos, como aqueles vinculados ao sentimento de "pertencer a algo", contribui com os processos escolares que envolvem as práticas de socialização. Assim, a escola é tida como lugar, para a Geografia, e está atrelada a inúmeros preconceitos que estabelecem conexões tanto emocionais, quanto físicas.

Na Grécia Antiga, o filósofo Aristóteles já destacava que, o que não está em um lugar não existe, atribuindo ao lugar ao sentido de "limite do corpo". As reflexões de Claval (2011, p. 229) vão ao encontro quando destaca que "[...] os lugares nos falam de enraizamento, do parentesco, do exotismo". Criamos vínculos com os lugares, os alunos, os professores, os funcionários desenvolveram ao longo dos anos laços afetivos com a escola, em virtude do ambiente fazer parte de seus cotidianos. $\mathrm{O}$ rompimento repentino dos elos, devido a pandemia de COVID -19, colaborou e está colaborando com as doenças psicossociais, porque "[...] o lugar é, em princípio, um espaço vivido: vivido, claro, pelos que lá moram ou trabalham quotidianamente" (SOUZA, 2013, p.36). Ou seja, vivenciam diferentes experiências nele dia após dia.

A escola é um espaço social, mas primeiramente é um lugar. Isso se comprova com o expressado pelo depoente F: "[...] a escola é o lugar onde eu fiz a minha primeira amizade, onde encontro meus colegas e amigos. É o único lugar onde pratico algum esporte, bom, é a minha segunda casa" (Narrativa 5 - Via WhatsApp em 20 de jul. 2020). Destaca também que o ambiente escolar colaborou e colabora com a formação de sua formação pessoal, porém, a depoente pontua, também, que com o isolamento e com o ensino remoto sente falta dos debates em sala de aula como mostra a Figura 3.

Figura 3 - Trecho das conversas do grupo do Whatsapp de uma turma do $3^{\circ}$ ano do Ensino Médio da rede estadual de Santa Maria/RS.

\section{Sobre a pergunta $\quad 17: 28$}

Saudade de realmente aprender alguma coisa,e debater sobre os assuntos

Tenho dificuldade em aprender em aulas EAD 
O lugar-escola se torna fundamental para ampliar conceitos culturais, sociais e principalmente, resgatar o sentimento de identificação com ele. O panorama atual levantou inúmeras questões, não apenas sociais e políticas, mas educacionais que estavam a mercê dos assuntos debatidos até então. Não se pensou tanto como no contexto atual, a escola como geradora não só de conhecimento e sabedoria, mas também impulsionadora de pensamentos críticos e capaz de salientar, principalmente, o sentimento de identidade. Estar identificado com a escola faz com que alunos, professores e funcionários valorizem ainda mais o lugar e transformam-no em um centro de construção de relações.

\section{CONSIDERAÇÕES FINAIS}

Cada ser humano carrega experiências/vivências, percepções e, de forma geral, suas próprias maneiras de se colocar diante do mundo. Esses conhecimentos são compartilhados com outros por meio de processos de socialização. Na infância e, posteriormente, na adolescência eles são divididos no ambiente escolar. Nesse processo, observa-se que o ensino de Geografia, por ter uma característica multidisciplinar, é um elo para a correlação entre os conhecimentos herdados, adquiridos nos lugares de vivência com os conteúdos curriculares. Desta forma, infere-se que tanto o profissional da área quanto os conhecimentos geográficos são essenciais para a sociedade, por favorecerem a visualização das diferentes problemática existentes nos grupos sociais, além de colaborarem com a resolução das mesmas.

Pode-se verificar que as instituições de ensino são imprescindíveis no fortalecimento das relações entre os sujeitos. Isso porque é na escola onde ocorrem debates, a reafirmação e, ao mesmo tempo, contraposição de ideias e o surgimento de diferentes perspectivas sobre um dado fato. Desse modo, as conexões, as discussões e as reflexões se intensificam nos ambientes presenciais, reafirmando, mais uma vez, a importância desses espaços, no momento em que assumem seus papéis de transformadores sociais. Com o isolamento social, ocorreu o distanciamento de maneira física e, também, emocional. As consequências desse período reafirmam a importância do convívio escolar, dos professores e alunos aprendendo em conjunto e com trocas presenciais.

Assim, a escola se manifesta como um espaço de identidade e, nesse sentido, possui amplo e significativo sentido para alunos e professores. Segundo Ferreira (2002, p. 48) "Quanto mais profundamente se está dentro de um lugar mais forte a identidade com ele”, assim, quanto maior o vínculo com a escola, maior a percepção de pertencimento a ela. Nesta maneira, para além de estar na escola como oficio, a escola se constitui um lugar indispensável na construção de valores sociais e se torna uma fonte identidade para cada aluno e cada professor. 


\section{AGRADECIMENTO}

O presente trabalho foi realizado com apoio da Coordenação de Aperfeiçoamento de Pessoal de Nível Superior - Brasil (CAPES) - Programa Nacional de Pós-Doutorado (PNPD - CAPES).

\section{REFERÊNCIAS}

ALVES, L. Educação remota: entre a ilusão e a realidade. Interfaces científicas: Aracaju, v. 8, n. 3, p. 348-365, 2020.

BATISTA, N. L. A Cartografia Escolar no processo de ensino-aprendizagem: o Hipermapa e sua utilização na Educação Ambiental, em Quevedos/RS. 139 f. (Dissertação de Mestrado). Programa de Pós-Graduação em Geografia. Santa Maria/RS: Universidade Federal de Santa Maria, 2015.

BRASIL. Ministério da Educação. Base Nacional Comum Curricular. Brasília, 2018.

BUTTIMER, A. Aprendendo o dinamismo do mundo vivido. In: CHRISTOFOLLETI, A. Perspectiva da Geografia. São Paulo: Difel, 1982.

FERREIRA, D. S; TONINI, I M. Há uma escola como lugar em período de pandemia? Ensaios de geografia, v. 5, n. 10, p. 27-32, 2020.

FERREIRA, D. S. Cine-geografar a Escola: um currículo geográfico a partir do lugar. 2019. 138p. Tese (Doutorado em Geografia). Programa de Pós-Graduação em Geografia. Instituto de Geociências. Universidade Federal do Rio Grande do Sul. Porto Alegre, 2019.

FERREIRA, L. F. Iluminando o Lugar: três abordagens (Relph, Buttimer e Harvey). Boletim Goiano de Geografia, v. 22, n.01, p. 43-72, 2002.

LEITE, A. F. O Lugar: Duas Acepções Geográficas. Anuário do Instituto de Geociências - UFRJ, 21, p. 9-20,1998.

LENZ, A. C; BATISTA, N. L; DE DAVID, C. Paisagem, pertencimento e escola: entrelaçando caminhos pedagógicos e culturais em Silveira Martins/RS. Terra Livre, v. 2, p. 406-425, 2019. 
MASSCHELEIN, J; SIMONS, M. Em defesa da escola: uma questão pública. Tradução de Cristina Antunes. 2. Ed. Belo Horizonte: Autêntica Editora, 2017.

MASSEY, D. Pelo espaço: por uma política da espacialidade. Rio de Janeiro: Bertrand Brasil, 2009.

PIMENTEL, G. S. R.; ARAÚJO, J. B. O.; OLIVEIRA, R. R. S. Estudo remoto emergencial em município do interior da Bahia: alguns apontamentos. Revista Educação Básica em Foco, v. 1, n. 1, abr. e jun. 2020.

RIO GRANDE DO SUL. Decreto 555.154 de 01 de abril de 2020. Disponível em: https://bit.ly/3bJClQT. Acesso em 21. jul de 2020.

RIZZATTI, M; SPODE, P. L. C; ERTHAL, D. B; FARIA, R. M. Avaliação geográfica para risco de COVID-19 em população a partir de 50 anos na área urbana de Santa Maria, RS, Brasil. Geografia Ensino \& Pesquisa, v. 24, e10, 2020.

SERPA, A. Uma Geografia que se pratica no dia a dia. Geosaberes, v. 1, p. 437-449, 2020.

SOUZA, Marcelo Lopes de. Os conceitos fundamentais para a pesquisa sócio-espacial. 1. ed. Rio de Janeiro: Bertand Brasil, 2013.

VARGAS, C. B; LAWALL, S. Reflexões biogeográficas acerca da origem, hipóteses, dispersão e distribuição dos Sars-Sov-2 (coronavírus). Geografia Ensino \& Pesquisa, v. 24, e19, 2020. 
